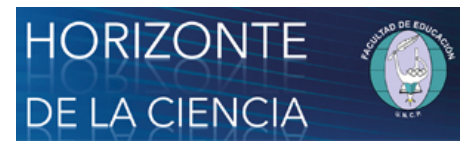

Horizonte de la Ciencia

ISSN: 2413-936X

horizontedelaciencia@uncp.edu.pe

Universidad Nacional del Centro del Perú

Perú

\title{
Educación valórica inclusiva y los desafíos de la educación religiosa para ser garante de tolerancia e inclusión social
}

\author{
Guerrero Díaz, Tatiana Patricia \\ Educación valórica inclusiva y los desafíos de la educación religiosa para ser garante de tolerancia e inclusión \\ social \\ Horizonte de la Ciencia, vol. 10, núm. 18, 2020 \\ Universidad Nacional del Centro del Perú, Perú \\ DOI: https://doi.org/10.26490/uncp.horizonteciencia.2020.18.401
}

Los autores otorgan el permiso a compartir y usar su trabajo manteniendo la autoría del mismo. Atribución no comercial (CC BY-NC) 4.0 


\title{
Educación valórica inclusiva y los desafíos de la educación religiosa para ser garante de tolerancia e inclusión social
}

\begin{abstract}
Inclusive axiological education and the challenges of religious education to be a guarantor of tolerance and social inclusion

A educação inclusiva de valor e os desafios da educação religiosa como garantidores da tolerância e inclusão social Llapn allip kaypa yachanarilihiwsu mana aatipana yachaynin,llapan nunakuna nunanila kawsayni likaku YOTANETANTSI ARIPEROTAKANTYARORI EJATZITA ANTSAINKIMATERO YOTANETANTSI KEMISANTANTSIKI KANTAKOBENTERORI PINKATSATANTSI MAROJEINI
\end{abstract}

Ogomeantagantsi kaninaro ntsëgotantatsi omagaro aike ora igenganepage Ira kemisantaigatsi inanatanëma kantëgotagantsi omagaroite timaigatsi

Tatiana Patricia Guerrero Díaz Datos de la autora Universidad Bernardo O'higgins, Chile

DOI: https://doi.org/10.26490/ guerrerotatiana21@gmail.com

iD http://orcid.org/0000-0002-8499-6583 uncp.horizonteciencia.2020.18.401

Recepción: 06 Marzo 2019

Corregido: 19 Septiembre 2019

Aprobación: 06 Octubre 2019

Recepción: 06 Marzo 2019

Corregido: 19 Septiembre 2019

Aprobación: 06 Octubre 2019

\section{RESUMEN:}

La clase de religión es un escenario de interacción educativa que no ha estado exento de las tensiones propias de su naturaleza evangelizadora y doctrinaria. Hoy en una sociedad convulsionada, cambiante y tendiente a la secularización; la clase de educación religiosa se posiciona esencialmente como un espacio de desarrollo y aprendizaje para la expresión de la libertad de conciencia y del derecho al juicio privado; espacio donde convergen las diferentes cosmovisiones históricas, culturales y teológicas de una comunidad que cohabita en el mismo espacio educativo y sobre la cual el profesor tiene el desafío de garantizar la inclusión y tolerancia en la aproximación respetuosa y empática hacia las diferentes alteridades de sus estudiantes. Es concluyente conocer el funcionamiento y normativa que rige las clases de religión en Chile, para situar en el contexto global las diferencias y similitudes del abordaje a la clase de religión en la educacional formal y el curriculum en ella representado, considerando las variantes epocales, de un sistema educativo que ha sido permeado por la visión religiosa colonizante y que se ha sido transformado vertiginosamente por medio de las transiciones que le han sucedido, lo que deviene en que el profesor de religión deba aguzar sus sentidos y ser creativo en las formas de comunicarse con los estudiantes, atendiendo a las nuevas aproximaciones epistemológicas, no solamente de la educación inclusiva, sino también desde los diálogos interreligiosos y ecuménicos, con miras a replantear y eventualmente reemplazar el subsector de religión por asignaturas de ética, axiología y religiones comparadas.

PAlabras ClaVe: Inclusión, tolerancia, religión, estudiantes, curriculum, identidad cultural, cosmovisión, pertenencia epocal, Llapalan, alliplikanakuy, rilihwsu, yachapakukuna, uylu, kikin kawsanin, pachakunalikay, kallaputunakuynin, marojeini, pinkatsatantsi, kemisantantsi, oinijantari, apotantsi kenkitsashiriantsi, apatokitachari yotanetantsi, amenakantsirori teonkantaityane, Netsabakagantsi, kabintsagantsi, kemisantagantsi, sangenanariei, kantëgotagantsi, kero obegiro agenganeegi, asi eiroegi.

\section{Notas DE AUTOR}

Datos deTatiana Guerrero Díaz, Doctora en Educación por la Universidad SEK, Magíster en Dirección y Liderazgo para la Dirección Educacional la autoraUniversidad Andrés Bello y Profesora de Educación Básica con Mención en Religión Evangélica de la Universidad Metropolitana de Ciencias de la Educación.

guerrerotatiana21@gmail.com 


\section{Abstract:}

Religion class is a scenario of educational interaction, which has not been exempted from tensions proper of its evangelizing and doctrinaire nature. Currently, we live in a troubled society, changing and tending to secularization; the religion class takes a stance particularly as an space for development and learning the expression of freedom of thinking and the right to the private judgement; an space where the different historical, cultural, and theological worldview on a community which coexists in the same educational space, over which the teacher has the challenge to guaranty the inclusion and tolerance in a respectful and empathetic approach towards the different otherness of its students. It is relevant to know the functioning and regulations, which rule Religion classes in Chile, to position in a worldwide context the differences and similarities of the approach to the Religion class in the formal education, and the curriculum represented on it, considering the epochal versions of an educational system, which has been infiltrated by the religious point of view from times of the Spanish colony in South America, which has been giddily transformed from the transitions occurred, which is translated in the fact the teacher of Religion should sharpen its senses and be creative in the way to communicate with its students, attending the new epistemological approaches, not only in inclusive education, but also from the inter-religious and ecumenical dialogues.

KEYwORDs: Inclusion, Tolerance, Religion, Students, Curriculum, Cultural Identity, Worldview, and Epochal Belonging.

\section{Resumo:}

A aula de religião se dá em um cenário de interação educativa que não está isento de tensões próprias de sua natureza evangelizadora e doutrinária. Hoje em uma sociedade convulsionada, que muda constantemente tendendo à secularização, a aula de educação religiosa se posiciona essencialmente como um espaço de desenvolvimento e aprendizagem para a expressão da liberdade de consciência e do direito ao julgamento privado. Espaço onde convergem as diferentes cosmovisões históricas, culturais e teológicas de uma comunidade que coabita no mesmo ambiente educacional, o professor tem o desafio de garantir a inclusão e a tolerância pela aproximação respeitosa e empática considerando as diferentes alteridades dos estudantes. É conclusivo conhecer o funcionamento e as normas que regem as aulas de religião no Chile, para situá-las no contexto global das diferenças e similaridades de abordagem da aula de religião na educação formal e em seu currículo. Considerando as variantes épocas de um sistema educacional que está permeado por uma visão religiosa colonizadora embora transformada vertiginosamente por transições ocorridas. Consequentemente o professor de religião deve estar atento e ser criativo nas formas de comunicação usadas com seus estudantes, atendendo às novas aproximações epistemológicas, não somente na educação inclusiva, mas também dos diálogos interreligiosos e ecumênicos com o escopo de repensar e eventualmente substituir o subsetor de religião por disciplinas de ética, axiologia e religióes comparadas.

PALAVRas-CHAVE: Inclusão, tolerância, religião, alunos, currículo, identidade cultural, cosmovisão, associação temporal.

\section{INTRODUCCIÓN}

El presente artículo tiene por objeto analizar el modo en que el curriculum oculto (Torres, 1998) y el currículum explícito (Eisner \& Vallance, 1974) de la clase de religión en Chile y de otros lugares de Latinoamérica que se vean representados en lo aquí mencionado, puedan convertirse en una apuesta de formación valórica garante de inclusión y tolerancia. Vivimos en un tiempo de diversos cambios culturales y paradigmáticos , lo que Beck (1998) denomina "la sociedad del riesgo"; no sólo en lo que a la educación religiosa refiere, sino que al situarnos en una sociedad inmadura convulsionada y cambiante, cómo describiría Bauman(2003) a nuestra época, es posible inferir que hoy la sociedad no se encuentra libre, sino en proceso de emancipación dado que:

[...] La sociedad es verdaderamente autónoma cuando "sabe que no hay significados 'seguros', que vive en la superficie del caos, que ella misma es un caos en busca de forma, pero una forma que nunca es definitiva ni eterna". La ausencia de significados garantizados -de verdades absolutas, normas de conducta predeterminadas, límites preestablecidos entre lo correcto y lo incorrecto, reglas seguras para una acción exitosa es conditio sine qua non de una verdadera sociedad autónoma y, al mismo tiempo, de la verdadera libertad individual; las sociedades autónomas y la libertad de sus miembros se condicionan entre sí. La seguridad de la democracia y de la individualidad no depende de la lucha contra las contingencias endémicas y la incertidumbre de la condición humana.' sino de su reconocimiento y de la decisión de enfrentar sus consecuencias.(Bauman, 2003:222-223). 
Es pertinente reflexionar sobre el concepto de libertad y sobre las consecuencias que la expresión de dicha libertad, puedan traer concatenadas en las definiciones a ratos disimiles sobre la libertad[1], es también oportuno que, por medio de esa reflexión, se puedan asociar libertad e inclusión, como partes de la interacción natural que ha de darse en un aula de convivencia saludable.

El conflicto se presenta cuando desde las expresiones de la clase de religión, no hay claridad semántica en lo que se entiende por "inclusión" dado que las denominaciones emanadas de la educación especial no responden a la diversidad que ha de ser acogida e incluida en el aula, por esto, la clase de religión tiene por desafío contribuir a la discusión de los significados y significantes de "lo inclusivo" porque afecta transversalmente como elemento del currículum escolar y como espacio de formación integral de los educandos.

Ocampo (2014) explica con claridad el dilema epistemológico que atraviesan las expresiones de educación inclusiva atendiendo a que están inmersas en un sistema diaspórico y sin acuerdos que clarifiquen que es lo que realmente requiere ser entendido como inclusión: "Levantar una perspectiva epistemológica en materia de inclusión obliga a establecer y a esclarecer las fronteras, las limitaciones y los encuentros necesarios entre inteligibidad, interpretación y comprensión de los fenómenos gravitantes en esta discusión” (Ocampo, 2014:87) Por esto es pertinente clarificar ¿Qué ha de atender la clase de religión como inclusión? Y ¿De qué manera se han de conducir los abordajes metodológicos pertinentes, que atiendan a las necesidades del educando, por sobre las voluntades particulares de los educadores o de las currículas formalizadas que le rigen?.

Tanta incertidumbre ha suscitado el sentido de la clase de religión en Chile, que para conocer cuál era el real sentido práctico de dicha asignatura, el PNUD (2016) y el MINEDUC (2016) licitaron una investigación que diera cuenta de lo que sucedía al interior del aula en las clases de religión del país, habiendo identificado que su sentido y "el propósito primordial de esta clase se encuentra en el ámbito de la promoción de un desarrollo de tipo ético-valórico" (Montecinos et al 2017:8) La asignatura de religión y el decreto 924 de 1983 (MINEDUC, 1983) que norma la obligatoriedad de ofertarla en todos los establecimientos educacionales del país que reciben financiamiento estatal, han sido cuestionados fuertemente durante los últimos años por diversos movimientos laicistas y ateístas, los argumentos que han relatado para la eliminación de la clase de religión no distan mucho de lo concluido por el estudio del PNUD en el año 2017 y que se analizará en este documento.

En la entrevista dada al diario electrónico el Mostrador (2014) La Sociedad Atea de Chile, manifiesta que su propuesta es modificar la actual clase de religión en la cual se "realizan catequesis de un credo particular, sustituyéndolas por clase de historia de las religiones, con el objeto de que puedan conocer todo el espectro de religiones que existen en el mundo" (Saleh, 2014 s/n).

Otro de los argumentos que se discuten para erradicar la clase de religión de los planes de estudio reglamentarios para las escuelas públicas chilenas; es la separación de la iglesia del estado en el año 1925. Por lo tanto, no es atribución del estado el velar por el conocimiento religioso de los educandos, sino que la adquisición de dicho capital cultural (Bordieu, 1997) se realice en el ejercicio privado del derecho a tener una religión, de igual manera arguyen que "es fundamental tener la categoría de Estado Laico expresamente en la redacción del futuro texto jurídico .Proponemos cambiar el actual artículo cuarto del capítulo de La Constitución de 1980 que dice Chile es una República democrática por Chile es una República Laica y democrática, o en su defecto Chile es un estado Laico y democrático" (Saleh, 2014 s/n)

Las voces disidentes a la clase de religión ( movimientos ateístas y laicistas) tienen también asidero en las consideraciones técnicas de la falta de preparación formal en pedagogía de muchos profesores en ejercicio, quienes, al no poseer herramientas didácticas, sino exclusivamente formación disciplinar en teología o ciencias de la religión, no tienen las competencias formales para el ejercicio pedagógico. Dicha carencia dificulta articular estrategias de inclusión, que se evidencien en enseñanza para todos los tipos de educandos que hoy conviven en las salas de clases. 
En defensa de la enseñanza religiosa al interior de las escuelas, es pertinente recalcar que la cultura religiosa es muy relevante en la formación de sujetos integrales y parte esencial para entender el pensamiento occidental (Scherz, 2015) citando lo expresado en la declaración de los planes y programas de Religión Católica aprobados por el MINEDUC, expresa que "dicha disciplina permite dialogar con los otros saberes y permitir a la persona descubrir un sentido para su existencia, encontrar respuesta a las grandes preguntas de la mente (filosóficas) y del corazón (vivenciales)" (Scherz, 2015:36) sumado a lo anterior, la clase de religión es prácticamente la única instancia para la formación en valores dentro del currículum actual; razón por la cual cabe plantear como duda razonable, la necesidad de proponer una alternativa curricular a la formación ética dentro de las escuelas públicas y subvencionadas del país y analizar su correspondencia social dentro del currículum latinoamericano y su prospectiva. Como Connell expresa: "La calidad moral de la educación se ve afectada inevitablemente por el carácter moral de las instituciones educativas" (Connell, 1999, pág. 22) y en esto se ha de comprender también, la intencionalidad del currículum y de las instituciones que lo diseñan en concordancia a las políticas vigentes.

\section{Consideraciones sobre la clase de Religión en Chile}

Al consultar a los directores de establecimientos educacionales sobre el sentido y aporte de la clase de religión en el desarrollo práctico sucedido al interior de sus colegios, el informe del PNUD reveló que : "las dos contribuciones son la promoción de valores para la formación integral de los/as estudiantes desde una perspectiva confesional religiosa (26,96\%); y la promoción de valores para la formación integral de los estudiantes, pero esta vez desde una perspectiva laica 9 (19,58\%)"(Montecinos et al, 2017:8)

Dichas contribuciones qué, si bien pueden sonar disonantes, ya que una rescata la clase de religión como un espacio de formación integral, donde la confesión religiosa y la dogmática asociada se hacen parte de este educando "integral" (Castillo \& Arias, 2016).Por otro lado, se expresa en menor porcentaje que los valores trabajados en la clase de religión, se abordan desde la perspectiva laica también asentando en su descripción a la formación de un individuo integral.

Las expuestas posiciones no son contradictorias y la combinación de las dos miradas, evidencia el apremio por definir un punto de equilibrio que oriente la contemplación y el marco de acción del docente; en el sentido que vaya siendo configurado el futuro curricular de la clase de religión, normando, planificando y diseñando los procesos de enseñanza aprendizaje de la asignatura religión sobre temáticas comunes, de modo que las dos posturas que consideran que la clase de religión es un aporte concreto al sistema escolar, puedan encontrarse en el punto común y dicha intersección permita que dialoguen desde los distintos programas de estudio como una modificación curricular menor[2] a lo ya existente, o que idealmente se generen nuevas propuestas curriculares es decir, una modificación mayor[3]; que converja en el desarrollo ecuménico[4] e interreligioso de un programa unificado y representativo de los credos reconocidos, que sean posibles de conglomerar por esta vía.

Sabiendo claro, que la segunda propuesta es más árida de concretarse, en virtud de que el diálogo interreligioso y el ecumenismo son procesos político-sociales complejos y que desafían a la nación a una unificación real y no solamente una vez al año en una celebración litúrgica común; como es el caso por ejemplo del tradicional "Te Deum[5]".

Para Muñoz (2013) Chile, como pocos países del mundo celebra un "Te Deum” (canto de agradecimiento a Dios) con motivo de sus fiestas patrias con una misa desde 1811, pero desde 1970 a solicitud del entonces presidente Salvador Allende Gossen el Arzobispo de Santiago Cardenal Raíl Silva Henríquez , invitó a otras confesiones cristianas a participar de esta liturgia haciéndola bajo cánones comunes, por tanto desde esa fecha dicha celebración religiosa tiene el carácter de ecuménica.

Retomando los planteamientos anteriores, una clase de religión de carácter ecuménico es históricamente plausible de ser implementada, atendiendo a los antecedentes de diálogo que preceden a las confesiones 
cristianas en Chile oficialmente al menos desde la década del 70. Es importante no generar segmentaciones a priori al contemplar la clase de religión como un elemento aislado en la historia o en los cambios sociales que vive el país o pensar en forma reduccionista al decir que no contribuye operacionalmente a la pragmática de competencias laborales, sino otorgarle la posibilidad de establecerse como parte del diálogo político y social del país.

El posicionar la clase de religión como un semillero para el posterior diálogo político de sus ciudadanos, sólo puede llevarse a cabo entendiendo que las trasformaciones sociales atraviesan al ser humano en todas sus posibles dimensiones y qué en estas, la religión debe mantener un espacio activo que también sea parte de las mencionadas transformaciones y cambios de la sociedad; y esas posibles dimensiones son inexcusablemente plausibles de ser abordadas en la asignatura de religión en todos los niveles de escolaridad donde se imparte, un ejemplo de esto es lo dicho por el Obispo auxiliar de Santiago Cristian Contreras Villarroel en 2011 y que Muñoz (2013) lo rescata:

[....]El desarrollo humano integral es una noción que aporta la enseñanza social de la iglesia y que hace referencia al conjunto de variables que deben concurrir para alcanzar el bienestar de las personas y la sociedad. Estas variables son mucho más que la pura economía, que sólo es una dimensión del desarrollo, necesaria pero insuficiente para dar cuenta de la riqueza del ser humano y sus múltiples dimensiones, como la social, la cultural y la espiritual y su vocación trascendente. El desarrollo humano integral involucra, además aquellos bienes colectivos como el medioambiente. El cuidado de la creación, a través de modos de vida, de producción y de consumo responsable y solidario con las actuales y futuras generaciones es, sin duda, un reto fundamental de la sociedad actual y requerimos leyes y políticas que lo favorezcan (Muñoz, 2013:112).

Esta clase de religión que atiende a las múltiples dimensiones del ser humano, debe aprender de la historia de su funcionamiento en los establecimientos educacionales del país y darse a la tarea de buscar nuevos rumbos, aunque eso implique replantear las bases epistemológicas que le han dado el carácter de asignatura "optativa" en una elección poco clara, ya que los educandos que "no optan"[6] por ella, muchas veces deben mantenerse al interior de la sala de clases en contra de la voluntad expresada por sus padres, ante la nula alternativa de actividades que complementen esas horas de clases y la falta de espacios y recursos humanos de los que disponen los establecimientos.

Para situar normativamente la clase de religión en el sistema escolar chileno el punto de partida es el Decreto 924 del año 1983 el cual establece en su artículo tercero:

[...]Las clases de religión deberán ofrecerse en todos los establecimientos educacionales del país, con carácter de optativas para el alumno y la familia. Los padres o apoderados deberán manifestar por escrito, en el momento de matricular a sus hijos o pupilos, si desean o no la enseñanza de Religión, señalando si optan por un credo determinado o si no desean que su hijo o pupilo curse clases de Religión.(MINEDUC, 1983:1).

En la práctica real existen escuelas no confesionales[7] que sólo dan la opción de religión católica romana en su ficha de matrícula contraviniendo lo establecido en el artículo cuarto que establece:

[...]Se podrá impartir la enseñanza de cualquier credo religioso, siempre que no atente contra un sano humanismo, la moral, las buenas costumbres y el orden público. Los establecimientos educacionales del Estado, los municipalizados y los particulares no confesionales deberán ofrecer a sus alumnos las diversas opciones de los distintos credos religiosos, siempre que cuenten con el personal idóneo para ello y con programas de estudio aprobados por el Ministerio de Educación Pública MINEDUC, 1983:2).

En los datos sobre el uso de los programas de estudio aprobados por el Ministerio de Educación que aquí se describen:

"los establecimientos públicos utilizan mayoritariamente sólo el programa oficial católico (en un 54,67\%), seguido de una minoría que usa sólo el programa evangélico (2,87\%). Sin embargo, existe un 16,66\% de encuestados que declaran que en su colegio se utiliza simultáneamente el programa católico y evangélico. En casos excepcionales (0,29\%) se menciona utilizar programas propios" (Montecinos et al, 2017:9). 
En la experiencia narrada por estudiantes en páctica y egresados de la Carrera Pedagogía en Educación Religiosa de la Universidad Sek y que pude recoger en diversos espacios de diálogo educativo como su jefe de Carrera, la coincidencia común está en lo que Torres(2012) explica como la fragmentación de la cultura escolar, en donde las necesidades de reproducción social que se materializan por medio del curriculum y el sentido epocal de dichas necesidades no se correlacionan, al no existir un propósito definido e identificable que genere puentes o al menos señaléticas entre lo etéreo y lo tangible ; la vertebración de los aprendizajes pierde la estructura, es decir como "los contenidos culturales que conforman el curriculum escolar venían apareciendo, con excesiva frecuencia, descontextualizados, alejados del mundo experiencial de alumnos y alumnas"(Torres,2012:20).

La clase de religión aparece muchas veces con un sentido indeterminado al momento de planificar la progresión de contenidos, es por eso que apremia la posiblidad de reunir curriculistas con experticia en la enseñanza religiosa que puedan diagramar con mayor lógica e innovar los programas de la clase de religión vigentes, curriculistas capaces de entender que la decolonización del poder y del saber (De Souza, 2010) es el requerimiento escencial para una enseñanza religiosa liberada de prejuicios.

En la definición de religión hecha por (Muñoz, 2018) es posible comprender que la diagramación sugerida para una innovación curricular pertinente de la clase de religión, deberá considerar el sentido bidirecciónal de lo colectivo y de la experiencia individual, "el término religión hace referencia tanto a las creencias y prácticas personales como a ritos y enseñanzas colectivas"(Muñoz, 2018:106).

En lo planteado por (Fleuri, 2015) la enseñanza religiosa se materializa en lo apremiante, la "necesidad de desarrollar nuevas perspectivas, fundamentadas en la justicia social que sean coherentes con los intereses del conjunto de la humanidad y con la autonomía de cada grupo sociocultural"(Fleuri,2015:39). En este sentido, la innovación de las curriculas que rigen la clase de religión deben ser capaces de decolonizar las perspectivas capitalistas y segregantes del conocimiento mudandolas por saberes comunitarios "se torna pués necesaria una resignificación epistemológica del conocimiento, que deconstruya la presunción moderna colonial de la universalidad de las ciencias y considere las complejidades y las ambivalencias producidas en el encuentreo entre los diferentes saberes y culturas" (Fleuri,2015:39).

La concepción de lo sacro y lo profano desde la mirada posmoderna, ha sufrido modificaciones a lo naturalizado como expresión religiosa occidental; donde lo positivista y empírico de la modernidad se manifestaba en lo religiosos a través de una visión técnico científica y económica hoy prevalece una visión holística multidirecciónal donde en palabras de Muñoz, se reconoce que la persona o "RES Sacra Homo es la realidad sagrada por excelencia" (Muñoz, 2018:36).

En la actualidad, la oferta programática de la asignatura de Religión en lo reconocido por el Ministerio de Educación de Chile (MINEDUC), parece ser muy amplia al dar espacio a religiones minoritarias como la fe BAHAI[8] y más de 40 confesiones cristianas diferentes, lo que en la práctica no se evidencia ya que para la evaluación docente debe presentar su programación en "religión evangélica que el programa es el unificado por le CONAEV o en religión católica romana; por lo tanto la aplicación del resto de los programas aprobados por el MINEDUC no tiene sentido si lo que se evalúa se mide con sólo esas dos visiones; de igual manera existen colegios no confesionales sólo contratan profesores de confesión religiosa católico romana para impartir la asignatura de Religión. Por tanto, la supremacía de sólo una visión religiosa en las aulas se muestra con el dogmatismo y proselitismo religioso ejercido sobre los alumnos en este tema, debido a que la mayoría de estos docentes imparten catequismo (enseñanza de doctrina) y liturgias a través de rezos, uso de sacramentos y dogmas provenientes de Roma, más que de los programas aprobados por el MINEDUC.

Sin perjuicio de lo anterior, también existe un considerable número de profesores de religión de confesión evangélica que carentes de formación pedagógica, replican lo que desarrollan en la Escuela Dominical de sus congregaciones y no sitúan los saberes de la clase de religión, en el marco de laicismo que define a los establecimientos educacionales no confesionales. 
Para que un buen profesor de religión pueda acercarse a las religiosidades populares y a la creencia de sus estudiantes, inevitablemente debe haber sido formado en metodologías y fenomenologías para la comprensión de los fenómenos religiosos. Parker( 1993) da cuenta del proceso paulatino de acercamiento a los fenómenos religiosos en los cuales un estudioso de las religiones debe estar compenetrado, para esto se hacen presentes competencias y habilidades de observación al fenómeno cultural, que alguien que no ha sido escolarizado en educación superior formal, tendrá serias dificultades para la implementación pedagógica demandada de un educador y para la ejecución metodológica y planificada de los procesos de enseñanza aprendizaje.

Como lo explica Parker (1993) “se comienza a estudiar la cosmovisión popular: su lenguaje, sus estilos de pensamiento, sus "gramáticas" culturales y simbólicas, sus categorías, incluidas, por supuesto, sus creencias y prácticas religiosas. Este estudio se ha hecho a menudo en una fecunda interacción intelectual-pueblo a través de procesos de educación popular o de investigación-acción" (Parker,1993:42). Un profesor de religión no deberá estar ajeno a la investigación-acción mencionada por (Parker, 1993) ya que es ese tipo de investigación, la que mejorará sus métodos y acercará la comprehensión de la religión en sus componentes desagregados hacia los estudiantes.

Rivard \& Amadio (2003) Realizaron un estudio sobre la cantidad de horas asignadas dentro del currículum formal a la enseñanza de la religión al interior de las escuelas públicas de 142 países determinando que en 73 de ellos, es decir el 51\% asigna horas lectivas y obligatorias dentro del horario oficial y que de los 69 países restantes que conformaban el $49 \%$ del estudio, estos a pesar de no tener espacios formales asignados dentro del horario de clases, de igual modo generaban actividades extracurriculares para la enseñanza de la religión, si bien en este estudio no aparece Chile como parte de los países que conforman la muestra, lo concluido por este estudio es perfectamente convergente con las necesidades que se han levantado como hallazgos de diversos estudios en la enseñanza religiosa nacional y también sobre las dificultades metodológicas en el abordaje y análisis de sus procesos de enseñanza aprendizaje, dado que:

[...] un estudio de los horarios oficiales no nos aclara plenamente la importancia atribuida a la religión en el currículo. Los objetivos que trata de conseguir el currículo, así como las metodologías utilizadas durante la transmisión de los contenidos, constituyen elementos esenciales en una reflexión global sobre este tema. Esto es tanto más cierto cuanto que esa reflexión suscita un interés cada vez mayor debido a que muchas sociedades están siendo más y más multiétnicas y multiconfesionales (Rivard \& Amadio, 2003:106).

La discusión de la enseñanza religiosa no es un fenómeno excluyente a Chile o Latinoamérica. Wimberley (2003) explica en razón de las múltiples confesiones europeas paulatinamente se ha logrado encontrar espacios comunes donde "la enseñanza de la religión comparada es normalmente obligatoria: los niveles se establecen y elaboran en la forma acostumbrada y la enseñanza la imparten maestros cualificados; en este esquema, suele recibir el mismo tratamiento de una asignatura como la educación cívica" (Wimberley,2003:91). En el caso de los colegios confesionales, es enfático en establecer una diferencia sobre la educación religiosa allí impartida, atendiendo a las particularidades de visión de cada credo, donde es muy difícil que se distingan los conceptos de catequizar[9] y educación religiosa como elementos diferenciadores, en virtud de que al situarse la educación en un contexto escolarizado religioso, se plantean desafíos importantes, no distintos a lo que también problematiza a los establecimientos confesionales chilenos en donde:

[...]"Los esquemas confesionales tienen que ofrecer un sistema de opciones sobre la base de la libertad de conciencia, y la enseñanza de la religión puede llegar a convertirse en una actividad casi extracurricular, con una categoría especial de profesores, procedentes con frecuencia de las comunidades religiosas. Consecuentemente, la distinción entre educación religiosa (aprendizaje de la religión) y la instrucción religiosa (aprendizaje de la práctica) puede ser más o menos clara, y en las escuelas religiosas privadas puede desaparecer completamente"(Wimberley,2003:91). 
El situar la clase de religión fuera de lo que acontece globalmente en las tendencias educativas es un error ya que no permite discutir acerca de lo que Belderraín (2003) Identifica como la problemática central que no ha permitido definir que cual es la esencia de la clase de religión y a que ha de corresponder su principal objetivo, entre muchas de las tensiones exógenas e internas que puede enfrentar la clase de religión "la tensión más profunda tiene que ver con la opción entre la enseñanza del hecho religioso, como hecho cultural e histórico, o la enseñanza de la práctica religiosa propiamente dicha"(Belderraín,2003:20), ya que al no existir una clara definición que lleve a definir el currículum a través de los programas de estudio, cada profesor de religión hará al menos en Chile, lo que considere más conveniente, como ya se mencionó anteriormente puede escoger por sobre 40 opciones de programas que el Ministerio de Educación considera aprobados.

\section{SObRe LA FORMACIÓN DE LOS PROFESORES DE RELIGIón EN CHILE}

Los profesores de religión en Chile se han formado de forma disímil a otras carreras de pedagogía, en virtud de que mayoritariamente han optado por la formación pedagógica, una vez estando en el ejercicio de funciones como profesor de religión, lo que en otras pedagogías sería impensado; para el caso de los profesores de religión se hace posible; en virtud de que en varios casos, han recibido primero la formación de la especialidad en los diversos seminarios teológicos de las confesiones cristianas o han sido habilitados en razón de su ejercicio eclesial como feligreses de alguna de las confesiones religiosas que están autorizadas por el Ministerio de Educación para otorgar esas certificaciones.

Cabe recalcar que ninguno de los seminarios teológicos evangélicos o de las confesiones protestantes cuentan con reconocimiento oficial del MINEDUC, por ende, las certificaciones que otorgan carecen de validación académica en la calidad de títulos o grados regulares, por esta razón para quienes han cursado estudios en los mencionados seminarios o institutos bíblicos, se torna imperativo cursar estudios regulares de pedagogía en alguna institución de educación superior reconocida. "La docencia debe ser una de las pocas profesiones, tal vez la única en la que existe una distancia tan significativa entre los contenidos de la formación y las exigencias para el desempeño" (Tedesco,2012:165). La formación de profesores de religión en Chile, es una tarea con muchos ejes pendientes, dado que en la promulgación del decreto 254 del año 1983 se dejó abierta la puerta para que personas sin formación en pedagogía trabajasen como profesores de religión con el mero de hecho de comprobar feligresía regular y antecedentes de formación teológica, con eso acceden al llamado "certificado de idoneidad" el que si bien da cuenta de ser una persona moralmente acorde a los principios que ha de enseñar, no es garante de un profesional capacitado para el desempeño del rol de profesor en procesos de educación formal en sus niveles primario y secundario.

En el estudio del (PNUD 2017) de los colegios considerados en la muestra se evidenció que "la mayor parte de los profesores poseen título de profesor de religión y cuentan con autorización de su respectiva iglesia (66.6\%). La segunda mayoría la constituyen profesores con título profesional de otras disciplinas y con autorización de sus respectivas iglesias (28,3\%)" (Montecinos et al, 2017).Estas cifras no son del todo clarificadoras, ya que no recogen la totalidad de los profesores de religión del país.

En una entrevista realizada a Alfonso Valenzuela, profesor de religión y ex director del Área de Pedagogía Religiosa de la Vicaría para la Educación, expresa que no hay claridad sobre el número de profesores de religión que ejercen en Chile, ya que en las cifras de la Vicaría para la Educación serían alrededor de 2000 profesores católicos habilitados con el certificado de Idoneidad, pero existen otras 30 confesiones religiosas autorizadas para otorgar dicha habilitación, la CONAEV [10], si bien no otorga públicamente el número de sus habilitados a nivel nacional, en una conversación informal con sus directivos, explica que existen alrededor de 100 habilitados en la región metropolitana y 100 en el resto del país, de este modo es complejo determinar la exactitud del número de profesores de religión.

No obstante al indeterminado número de profesores de religión en ejercicio; en relación a la población ya conocida, si es posible determinar las brechas que limitan su desempeño docente, Valenzuela (2018) 
identifica tres carencias específicas en la función actual de los profesores de religión: 1.carencia en la integración de las disciplinas educativas y pedagógicas, 2. se debe realizar más investigación con miras a desarrollar estrategias didácticas en la enseñanza religiosa y 3. Se debe incorporar a los profesores de religión a las exigencias de la carrera docente y su perfeccionamiento continuo.

En razón de dar cumplimiento cabal a lo exigido en la nueva ley de carrera docente chilena Ley 20.903, se debe iniciar por normalizar la situación de profesores de religión en ejercicio que no tienen la carrera de pedagogía cursada ni en pregrado ni segunda titulación y que sin ese elemento mínimo no pueden acceder a la exigencia de educación continua y vagamente podrán cumplir con las evaluaciones que les estratifican en los diferentes tramos del quehacer profesional.

Por otra parte, los profesores de religión sin escolarización superior completa, no poseen herramientas técnicas que les permitan desarrollar estrategias que adapten o flexibilicen las currículas vigentes para la diversidad de educandos con los que tienen que trabajar, cuando se desarrolla el concepto de inclusión es necesario salir del paradigma patologizante que segrega y etiqueta a los estudiantes, el diálogo comprensivo en el desarrollo de la alteridad de procesos educativos para todas las personas es la clave para una clase de religión inclusiva, más allá de las evidentes similitudes o diferencias que enriquecen la variable "humana".

El avanzar en una educación religiosa inclusiva va directamente ligado a comprender a los educandos en su dimensión sistémica y epocal, como bien plantea Ocampo (2018) "La comprensión epistemológica de la Educación Inclusiva asume el desafío de resolver al problema de la ontología social que afecta a la legibilidad de los grupos sociales" (Ocampo, 2018:36) sumado a lo anterior, la pertinente inclusión y desarrollo de los valores de Tolerancia y respeto a la diversidad y alteridad de los sujetos, son plausible de vivenciar sólo al deconstruir las limitantes epistemológicas que vulneran el sentido esencial de la inclusión; "En relación a la naturaleza post-disciplinaria de la Educación Inclusiva, se reafirma, la necesidad de construir un conocimiento educativo "otro" y "heterotópico", es decir, un saber auténticamente nuevo, coherente con las demandas, tensiones y sujetos educativos concretos" (Ocampo, 2017).Es decir, si el profesor de religión en el Siglo XXI, no tiene la capacidad de deconstruir los prejuicios propios de su naturaleza catequizada, difícilmente podrá atender a los sujetos heteronómicos que le serán puestos bajo supervisión y guía en la sala de clases.

Por esto, la formación de los profesores de religión hoy más que nunca, enfrenta el desafío de recomponer las currículas y avanzar hacia un desarrollo heterotópico de la enseñanza de la religión, también debe preocupar a los formadores de profesores de enseñanza religiosa que la oferta de plazas de trabajo para el cargo de profesor de religión no alcanza a ser cubierto en su totalidad por las cohortes que egresan de las Universidades que forman profesores de religión ya que el número de profesores en ejercicio y en procesos de egreso es significativamente menor a la oferta laboral existente, esto podría considerarse una buena noticia dado los favorables índices de empleabilidad que esto evidencia, sin embargo las formación de profesores de religión va a la baja y muchas entidades de educación superior chilenas ya no ofertan esta carrera.

\section{INCLUSIÓN PARA VARIAR}

Hablar con propiedad sobre inclusión es sin lugar a dudas de una complejidad latente que también es extrapolada a diversos campos del saber, como lo explica (Ocampo, 2014) el desafío de realmente incluir, es poder abordar una educación para todos y desvincularse de la nomenclatura meramente científica y patologizante, que desde la mirada de la exclusión, segmenta y categoriza a los educandos según su grado o forma de ser distintos a lo que se pueda considerar la norma, y de ahí que se etiquete como comportamiento normal a los que son sistémicamente típicos.

Se debe reconsiderar la mirada sobre el sujeto que ha de ser modelado e incluido en este espacio de educación religiosa "pues pensar una posible pedagogía de las diferencias no requiere visibilizar su objeto de estudio a partir de los clásicos sujetos sociológicos en situación de exclusión”(Ocampo,2014:89). Por eso 
este apartado de "inclusión para variar" expresa la necesidad de cambios y variaciones que necesita vivir el educador para reconsiderar el mundo interno de cada estudiante y las múltiples singularidades que se integran y cohabitan dentro de la sala de clases.

El comprender que los desafíos planteados para la educación inclusiva son atingentes y de pertinencia absoluta del educador religioso, otorgará herramientas y nuevos enfoques para una producción cultural no colonizante, es decir, que rompa con los estereotipos reinantes de siglos anteriores y que decodifique las necesidades del estudiante con los parámetros y códigos de la cultura en la cual este se identifique, con las señaléticas e idiomáticas que le sucedan y con los colores e identidades que le sean favorables.

Pensar la inclusión en términos de alteridad, es decir, la condición de ser un otro singular y diferente; es dar el estatus de individuo que cada persona merece por la sola condición humana que le precede. Souza(2018) Concluye que "la alteridad comienza en la desigualdad, camina por el escuchar al otro y desemboca en una relación ética”[11](Souza,2018:120)

¿Cómo entonces la clase de religión puede acoger a la desigualdad en la diversidad de identidades sexuales, de las diferencias religiosas, de las diferencias culturales, de las diferencias lingüísticas, diferencias en los estilos de aprendizajes, diferencias en los tipos de inteligencias, diferencias en el hecho de ser distintamente humanos? La respuesta está en tomar conciencia de la alteridad por medio de la comprensión de las diferencias y que estas diferencias sean la ruta de diagramación de las nuevas formas de aprender la religión.

Las formas para construir rutas amables que acerque el concepto de religiosidad en el periodo escolar deben ser basadas en lo que Souza (2018) detalla diciendo que "la fe religiosa comprendida como experiencia de Dios genera amor, comunión e inclusión y esta puede ser entendida como un momento de significación" (Souza,2018:46)[12]. Si la clase de religión logra el objetivo de convertirse en un momento de significación, habrá cumplido el mayor de los desafíos para un educador el poder generar aprendizajes significativos como planteaba Ausubel (2002) es decir, aprendizajes que vinculen las experiencias de vida que trae el estudiante y le conecten con el nuevo desafío de conocimiento que le plantea el profesor; por lo tanto, de esa mezcla de saberes se cree un conocimiento nuevo que permanezca en el tiempo dado que para el estudiante posee un significado que le enlaza a sus memorias y experiencias de vida.

La clase de religión tiene por desafío generar reflexiones críticas que estimulen la libertad de consciencia, y por medio de la expresión de las libertades individuales, vivencie la importancia de compartir con otros y de ser una comunidad. Es en la identificación empática de las necesidades del otro donde pueden cimentarse los valores de equidad y justicia social que la educación religiosa promueve, la educación religiosa tiene por desafío que el docente que la imparte pueda abordarla desde una perspectiva sistémica que tiene en cuenta los valores y creencias de cada educando, en lo postulado por (Cordero, 2014) este profesor de religión debe ser flexible y estudioso para entender los mitos y ritos que practican sus estudiantes y para aceptar que cada persona establece los mapas que delimitan su existencia en razón de :

1. "los valores y creencias imperantes en su familia.

2. el permiso que cada sistema autoriza para poder mirar unas cosas u otras.

3. la cultura de la que proviene.

4. la generación a la que pertenece

5. el momento histórico que le ha tocado vivir"(Cordero,2014:88)

La clase de religión es generadora de significados y por lo general reproductora de la cultura del país, el desafío para los educadores, al abordar la alteridad en la clase de religión, es que los significantes individuales desprendidos de los significados comunes logren situarse en el respeto y expresen tolerancia en la forma de asir los contenidos y comunicarlos, esto es lo que diferenciará a una educación oportuna y la desarraigará de la precarización colonialista de las ideas.

[...]La producción de alteridades, de sujetos en alteridad, de prácticas en y para la alteridad y discursos bajo esta directriz, construye una realidad que débilmente ha contribuido a sentar precedentes básicos para avanzar en nuevas formas de re-significación social, cultural y educativa....."Saber reconocer e interpretar 
las formas de presentación que adopta la desigualdad, la exclusión, la segregación, la desventaja social, la extranjería, la discapacidad y las necesidades educativas especiales (Unesco, 2009) en el marco de su eficacia simbólica (Bourdieu, 1991) devela una construcción teórica, social y cultural incompatible para subsanarlas, con respecto a la oficialización de un nuevo y actualizador sistema de sustentación en materia de justicia social oportuna para los desafíos del nuevo siglo (Ocampo,2014:93).

Al hablar de inclusión ha de considerarse el componente de multiculturalidad que tanta resistencia ha tenido en los procesos de reproducción colonizadores al interior de las aulas de educación religiosa, que violentan las percepciones diferentes a la espiritualidad judeo cristiana y paradojalmente también se contraponen a la prédica de un Dios de paz, pero aún hay profesores de religión que persisten en dichas práctica sobre las espiritualidades nativas o expresiones orientales de la fe.

Pozzer \& Wickert, (2015) Advierten del peligro de estas prácticas al interior de las escuelas públicas diciendo que la construcción teórica de los procesos educativos religiosos que abarca la diversidad cultural y religiosa corre el riesgo de ser sustento de concepciones etnocéntricas y monoculturales y que la educación religiosa de perspectiva intercultural no se reduce a la socialización de conocimientos. Sino, a la socialización de experiencias en un constante ejercicio de convivencia que reconoce y valoriza las raíces del otro y comprende el sentido de alteridad en la experiencia religiosa que valora la experiencia y cosmovisión presente y pasada , explican además que los teóricos de la educación religiosa que generan tensiones para las prácticas inclusivas son los mismos que generan un espacio restrictivo para legitimar la religión en la sociedad "son de carácter monocultural, exclusivista e impositivos, utilizando los dineros públicos para beneficiar apenas a sus egos y currículos añejos, por lo tanto pocos son los beneficios y contribuciones para una educación humanitaria e intercultural”[13](Pozzer \& Wickert,2015:91).

\section{UNA PROPUESTA A LA CONTROVERSIA QUE PROVOCA LA CLASE DE RELIGIÓN EN LA ACTUALIDAD}

El escenario de las confesiones y manifestaciones religiosas en Latinoamérica ha sufrido diversos cambios que sustancialmente modifican la percepción de la sociedad en su conjunto sobre esta materia , lo explica Bahamondes diciendo que "Entre los factores exógenos destacan los procesos de internacionalización de las naciones latinoamericanas, motivadas por el avance de la globalización y el consecuente acceso a nuevas tecnologías de la información, que permitieron conocer expresiones religiosas foráneas y asimismo difundir las propias" (Bahamondes,2012:111)

Las nuevas religiosidades tienen múltiples expresiones desde lo que han tomado del esoterismo, teosofismo y otras múltiples variantes no tradicionales como las restricciones alimenticias o curaciones alternativas, sin embargo es el sentido de trascendencia lo que no ha mutado de una cosmovisión religiosa a otra, existen raíces comunes inherentes al ser humanos tales como su necesidad de religar, es decir la conexión con la materialización de lo divino no ha sido ajena a ninguna cultura a través de la historia de la humanidad y desde lo expresado en la pintura rupestre de la prehistoria hasta las manifestaciones de hoy, se podría incluso considerar que la búsqueda de lo trascendente es casi un instinto tan elemental como el instinto gregario:

[...]Lo importante no son los cambios de las mediaciones, sino la transformación de su sentido y su lugar en el interior de lo sagrado. Pues tales mediaciones no son tomadas como prescripciones de una intervención divina anterior, ajena y externa al sujeto. Son expresiones de la necesidad de trascendencia que reside en el sujeto y que le permite realizarla históricamente, manifestarla culturalmente, expresarla socialmente (Muñoz, 2018:92).

En virtud de que la expresión de la religiosidad ha sufrido cambios en la sociedad y los procesos de escolarización formal y el currículum que les define debe estar acorde a los cambios sociales, cabe entonces plantear nuevos desafíos para el manejo ético y no proselitista de la asignatura de religión, evidenciando criterios en los cuales los educandos tengan la opción de discernir de modo informado, para esto la clase 
de religión u orientación religiosa, debe proveer una visión de las diversas religiones desde la perspectiva histórica y comparativa. Dando la posibilidad que los alumnos opten y cuestionen el conocimiento religioso. (Cordero,2014) plantea que:

"Cada familia tiene valores diferentes conformados a través de la interrelación con el medio con el que han vivido, sus tradiciones, la religión que han profesado, etcétera “...Un profesorado sistémico tiene en cuenta estas peculiaridades familiares, manteniéndose al margen de juicios o preferencias y aceptando las diferencias que marcan la procedencia de cada alumno" (Cordero, 2014, págs. 88-89).

No es recomendable perder de vista que el fracaso de algunos profesores en esta área se debe a que no consideran al planificar sus clases las necesidades y requerimientos de los propios estudiantes; olvidando que la perspectiva central y el target de la asignatura de religión ha de ser las necesidades de orientación socio valóricas en los educandos contextualizadas en la cosmovisión inherente a la época que les tocó vivir. Para estos fines los programas vigentes aprobados por el Mineduc para las más de 40 confesiones cristianas y los contenidos allí planteados son altamente moldeables; por tanto, si el profesor comprende los cambios que están sufriendo los adolescentes, como curiosidad vital inherente a los seres humanos más allá de la época que les tocó vivir tendrá la capacidad de contextualizar el saber religioso de forma tolerante, inclusiva y con pertenencia epocal.

Pajer (2015) Identifica tres paradigmas en los cuales se sitúa la enseñanza religiosa escolar europea: Político-concordatario donde el planteamiento didáctico es político confesional, Académico-curricular que plantea desde lo Planteamiento trans-confesional, inter/transreligioso, y el Ético-valoría que establece una aproximación didáctica de planteamientos ético, transreligioso, inter-conviccional, en los nombrados paradigmas coexisten las mismas competencias o habilidades que se ha evidenciado en América Latina son importantes de considerar al momento de replantear la clase de religión.

Para la justificación de la importancia de la enseñanza de la religión en concordancia con los Derechos del Niño en el Espacio Europeo (Wimberley, 2003) cita a la Convención Europea de Derechos Humanos $(\mathrm{CEDH})$ : “1. La libertad de pensamiento, conciencia y religión (CEDH, artículo 9) y 2. La educación de los niños respetando las convicciones religiosas y filosóficas de los padres (ibídem, protocolo 1, artículo 2)" (Wimberley,2003:96); En este sentido, la clase de religión, de cultura religiosa, de historia de las religiones o como se convenga su nominación en los diferentes países, está enmarcada como parte de los derechos humanos y como tal debe ser atendida por la formalización de las currículas, definiendo entre sus propósitos el enseñar la tolerancia y el respeto como ejes centrales de su formación.

En lo identificado por el estudio del PNUD (2017) se distinguen cuatro escenarios para la consideración en políticas públicas que redefinan los conceptos de la clase de religión. (Montecinos et al, 2017: 214-222)

- Escenario 1. Dos Alternativas De Clase: Clase De Religión Confesional O Espiritualidad Y Ética: Se propone proveer de dos asignaturas paralelamente la primera basada en los dogmas de las dos religiones mayoritarias ( católica y evangélica) y la segunda "además de abordar el desarrollo ético y valórico, necesitaría tener como foco propiciar experiencias educativas que promuevan la reflexión sobre la existencia humana, su sentido, finitud y trascendencia, de manera que los estudiantes comiencen a buscar respuestas a las grandes preguntas que acompañan al ser humano". (Montecinos et al, 2017:215-216)

- Escenario 2. Una Alternativa De Clase: Historia De Las Religiones: Se perfila como una asignatura de carácter obligatoria que pueda dar visibilidad a las confesiones religiosas minoritarias y enlace a una comprensión histórica de los fenómenos sociales que se han modelado a través de las religiones mayoritarias. Sin embargo, la dificultad aparece en el caso de los colegios confesionales donde la clase de religión dogmática es garante de libertad de culto.

- Escenario 3. Dos Alternativas De Clase: Clase De Religión Confesional O Historia De Las Religiones : La idea es ofrecer la clase como electivos, el primero con carácter confesional es decir doctrina y fundamentos de los dos credos mayoritarios del país (católico y evangélico) y como segunda opción una clase de historia de las religiones que se diferencia de la opción $n^{\circ} 1$ " clases de espiritualidad y ética" en que "el enfoque 
de espiritualidad y ética no considera necesariamente la visión religiosa, ya que es posible promover un desarrollo espiritual y ético sin considerar la sabiduría de las religiones (por ejemplo desde la perspectiva del autoconocimiento o de la conexión con la naturaleza)" (Montecinos et al, 2017:219)

- Escenario 4. Dos Alternativas De Clase: Clase De Cristianismo O Espiritualidad Y Ética : El propósito de la primera alternativa es generar una fusión ecuménica de los principios del cristianismo que son comunes a las confesiones católicas y evangélicas y son la base de la cultura occidental, esto como oferta académica a quienes busquen principios confesionales al interior de la clase de religión y recoger lo propuesto en el escenario 1 de una clase no confesional que dignifique la dimensión de la espiritualidad humana desde una visión más laicista, el cambio significativo de este escenario con la actual clase de religión es que tengan incidencia numérica en el promedio y promoción escolar

En las cuatro políticas identificadas como plausibles de implementarse en remplazo de la actual asignatura de religión ; cabe señalar que el desarrollo de la espiritualidad no debe desprenderse de la dogmática en exclusivo, el enseñar desde una perspectiva evangelizadora es una necesidad empírica de la iglesia, y no por dicha necesidad en la clase de religión hemos de olvidar lo dicho por Muñoz (2018) en relación a la necesidad de renovación de la iglesia deja una interesante reflexión sobre la enseñanza de la espiritualidad.

[...] En el aspecto espiritual, a veces hemos cultivado una especie de piedad bastante superficial. La piedad hecha solamente de cantos fervorosos, de predicación encendida está muy bien, pero no tiene suficientes raíces y entonces cuando sobrevienen situaciones difíciles fácilmente se diluyen, o lo que es peor, son llevada a expresiones espectaculares que no me parece que tienen la profundidad y la seriedad que tiene el Evangelio (Muñoz, 2018:80-81).

Por consecuencia la orientación en temas como sociedad, tribus urbanas, sexualidad, adicciones y otros, es trascendental. No tratada epistemológicamente con la exactitud de la biología u otra ciencia exacta, sino con la visión humanista de las necesidades del hombre, mostrando a través de textos sacros e históricos, que las necesidades humanas no han cambiado en su trasfondo si no que sólo han sido modificadas en su forma. Permitiendo que los alumnos se empapen de una visión filosófica holística. (Dado que la clase de filosofía ya no se imparte en las escuelas públicas y subvencionadas de modo obligatorio, la asignatura de Religión ha de subsanar ese vacío). Que integre el conocimiento social con los valores provenientes de las verdades universales que rigen el orden de lo bueno y lo malo, y norman a las sociedades para un bien común.

Al mirar lo estudiado por Moya \& Vargas (2017), en la comparación de cómo se implementas las clases de religión en América Latina y Europa, es atingente el cuestionarse" ¿Qué tipo de educación Laica o qué tipo de Educación Religiosa son necesarias para que la formación valórica de los educandos realmente ofrezca un espacio para la enseñanza de la tolerancia y que la cohesión social sea aprendida y entendida desde la reflexión acción?

[...]el prolongado debate sobre la laicidad o confesionalidad de la educación ha impedido el verdadero debate de fondo acerca de la contribución de la educación de la ciudadanía democrática y de las identidades colectivas. Para ello será necesario que desde el campo religioso y desde el campo laico se avance no sólo el mutuo reconocimiento de la legitimidad de las diferencias sino en la valoración de las mismas(Moya \& Vargas, 2017:29).

En lo dicho por Wimberley (2003) explicando sobre el proceso que ha vivido Europa para llegar a acuerdos comunes sobre lo que debe ser la clase de religión, dice que "el problema principal en la definición del proyecto ha sido cómo integrar la preparación para el diálogo religioso en el enfoque más amplio de la educación intercultural" (Wimberley,2003:89). La herencia atea de los países que vivieron en regímenes del comunismo, las poblaciones gitanas, la migración musulmana desde áfrica, el judaísmo y la habitual e histórica disputa religiosa que definió muchos de los periodos de guerra y paz al interior del continente europeo entre catolicismo romano, catolicismo ortodoxo y las variantes del protestantismo; hacen que abordar ejes comunes para la clase de religión no sea una tarea sencilla, pero no por ello, sea una tarea imposible; ya que debe quitar la concepción que a veces se tiene de conocimientos secundarios o "blandos", relegados al final de otras materias como matemática, literatura o ciencias, sin entender que la importancia curricular radica 
en que "la enseñanza convencional de la religión -conocimiento sobre la religión-, igual que ocurre con la competencia lingüística, se presta más fácilmente a esta integración que las variables actitudinales, como la empatía"(Wimberley,2003:94)

Da Silva, (2015) propone que postular principios generales para una educación religiosa no confesional; ayuda a dar valor a los conocimientos que deben ser tratados, diagramados y aprendidos en la escolarización formal, destaca tres principios que cabe resaltar en el tratamiento no confesional de la asignatura de educación religiosa:

1. [...]Tolerancia, no en el sentido negativo de "soportar" la diferencia, sino en reconocer que esa otra persona tiene valores propios que pueden diferir de los míos ya que pertenecen a grupos y culturas diferentes y que no tienen que ser observados con mi mirada cultural. El ser tolerante es un proceso progresivo ya que requiere además de conocer las convicciones del otro, tener una actitud respetuosa independientemente de las diferencias.

2. La reciprocidad es una actitud que debemos valorizar y desarrollar en el diálogo, convivencia y acciones junto al otro, así la práctica educacional estará realizando una verdadera educación democrática...Sin ejercer una violencia moral, tanto junto al educando como a los comentarios provenientes de contextos religiosos fundamentalistas, también en relación a los educandos que profesan convicciones ateas; en las relaciones que establezcan con sus compañeros que tienen o no convicciones religiosas.

3. En la vida pública el desafío está en la afirmación de civilidad, o civismo es decir en reconocer al ser ciudadano, y la valorización de una ciudanía que reconoce el vivir juntos es lo que posibilita la capacidad de reflexión y moderación en la expresión pública de sus convicciones" (Da Silva, 2015:141).

Otra consideración importante es no perder de vista la progresión de las visiones religiosas desde el panteísmo naturalista, pasando por la colonización cristiana para llegar en estos días a la progresiva secularización de los países Latinoamericanos, anteriormente en una ponencia realizada el 2017 en la PUC Minas, Brasil, persistí en señalar que el aprendizaje ya sea religioso o moral, no es sino la consecuencia de la historia de la evolución del pensamiento de diversas culturas que se han fundido en lo que hoy conocemos como las costumbres religiosas que enseña la clase de religión, ya que:

[...]América Latina es una fructífera cuna del sincretismo cultural compuesto por las expresiones nativas y de la cultura judeo- cristiana; ya que en todas sus prácticas mezcla la mitología y la veneración de los a los elementos de la naturaleza, con el cristianismo ya sea de índole romano u otros que colonizó el continente. Religión que no sólo ha heredado la lengua de nuestras naciones ya sea esta Portugués o Español, sino que también ha modelado la expresión cultural de la moralidad y el uso de la regulación ética como norma de la costumbre y no siempre del bien común (Guerrero, 2017,p.3).

Para entender los desafíos de la enseñanza religiosa en los procesos de secularización que ha desatado la globalización, se debe considerar la historia que ha vivido la fenomenología religiosa latinoamericana desde sus inicios, para comprender su progresión de fervientes creyentes a creyente nominales o sin afiliación religiosa, sabiendo que en la actualidad "el hecho religioso protagoniza las tensiones del presente por vía de su negación, a través de la progresiva "secularización” que acompaña como ingrediente necesario al fenómeno de la globalización capitalista” (Belderraín, 2003:20). La secularización en los procesos sociales puede o no considerarse una amenaza a la educación religiosa al interior de las escuelas; pero claramente es una señal que ha de atenderse en los nuevos diseños de procesos de enseñanza de la religión, con el objeto de ser real garante de inclusión de todas las expresiones de la fe humana, incluso el ateísmo como corriente de la "no fe".

El reto de educar religiosamente en tiempos postmodernos no está exento del desafío común de otras pedagogías sobre alfabetizar críticamente a los educandos, es decir propender a una educación religiosa que cuestione los dogmas para encontrar un sentido personal y reflexivo de la fe y de la espiritualidad Costa (2006 en Pozzer 2015) explica que:

[...] En un ambiente educativo en que se enseña a leer y escribir desde la alfabetización crítica se cuestiona el discurso, el poder y la ideología en el texto, así como el modo en que estos influyen en el lector. Este cuestionamiento está enmarcado en la acción transformadora y es consistente con la perspectiva comunicativa, una de las corrientes de la pedagogía crítica (Costa 2006:50). 
Es sabido que en el mundo occidental uno de los elementos centrales de la clase de religión es la enseñanza Bíblica. Sin embargo, no siempre los profesores a cargo de la educación religiosa poseen la capacidad exegética en el uso de una correcta hermenéutica que considere el contexto histórico y social de lo escrito; el contexto cultural de a quien estaba dirigido el mensaje cuando fue emitido y explique cómo esas enseñanzas pueden ser atingentes y contextualizadas con un sentido epocal contemporáneo y pertinente a los procesos y trasformaciones culturales que está presentes en la cotidianidad de los educandos.

Ese desarrollo crítico de ideas atiende a que el profesor se cuestione primeramente su comprensión de la religiosidad y por medio de esa reflexión continua pueda guiar a los educandos a leer cuestionando todo lo que están aprendiendo; Costa (2006) plantea la intencionalidad de todo los textos que se hacen parte de las currículas formales, diciendo que "desde la alfabetización crítica se entiende que ningún texto es inocente, que todo texto está cargado de ideología”. (Costa, 2006:50). Por tanto si todos los textos se encuentran cargados de ideologías, la labor docente no ha de centrarse en la transmisión y reproducción de dichos textos; sino más bien en guiar a que los estudiantes encuentren sus propios juicios de valor sobre lo leído sin perder de vista que el foco de la formación es la ética para una ciudadanía responsable; al formar profesores o al reflexionar sobre la práctica de profesores en ejercicio se debe "poner atención sobre la necesidad de preservar, reconstruir o potenciar los espacios e intersticios de relativa autonomía de los docentes en los establecimientos escolares de manera de poder decidir la posición desde la cual ejercerán su labor pedagógica en la formación de los ciudadanos".

\section{Conclusiones}

La clase de religión es un espacio de reflexión académica que debe atender en sus diferentes expresiones y formas de implementación (clases confesionales o valóricas), a todas las manifestaciones de espiritualidad que profesen los estudiantes y así también valorar en su diversidad a las diversas identidades y condiciones del ser humano.

La clase de religión ha de brindar pertenencia de espacios reflexivos en la manifestación del respeto y tolerancia como el sello de la inclusión y de los valores característicos de la propia naturaleza de la enseñanza religiosa y su mensaje de buenas nuevas. Debe considerar espacios que provean un lugar propicio para el diálogo, en el cual la libertad y la igualdad se enseñen de la mano a la propia identidad cultural y aprecie las identidades culturales y particularmente humanas que se intersecan en una visión común, proveyendo elementos de conocimientos que le permitan a los estudiantes la elección de la propia identidad religiosa y que inunde las mentes con amor al saber y haga del culto a un "Ser Superior" una experiencia ligada a la razón.

$\mathrm{Al}$ analizar la normativa y legislación vigente tanto de la clase de religión como parte del curriculum lectivo de la educación básica y media en Chile, como así también considerar los cambios en la legislación que rige la carrera docente, muchos son los desafíos que tiene por delante el profesor de religión, quien tiene la labor moral de ser un agente promotor de la tolerancia y el respeto a las diferencias culturales, religiosas y de otra índole.

Es posible también considerar el remplazo del subsector de religión por alguna asignatura cuyo currículum abarque desde la ética y la axiología, hasta la responsabilidad social, política y valórica que un individuo tiene ante su país, pero dicha transformación debe ser procesual y consensuada atendiendo las reales necesidades de transformación cultural y respondiendo a las interrogantes elementales del currículum y a su intencionalidad.

No se debiera permitir que la erradicación de la clase de religión de paso a currículas acríticas y sin sentido axiológico explícito, por eso la principal defensa a la permanencia de la clase de religión en las currículas escolares es la transformación que le permita responder a los desafíos de una educación para todos los tipos de educandos que existen en sus particulares diversidades y aproximaciones sociales.

La educación religiosa tiene por delante múltiples desafíos de integración y de aprendizajes sobre la diversidad, la multiculturalidad y las nuevas espiritualidades, no difiere de los desafíos de todo educador con 
espíritu crítico y social Freire (2001), hablaba de que las prácticas educativas deben ser descubiertas en los componentes fundamentales de la cultura que primero aprendió por la magia y posteriormente se hizo a la ciencia para que se pudiera aprender más y enseñar más. Decía que:

[...]Si los seres humanos no hubieran llegado a ser capaces- debido entre otras cosas a la invención del lenguaje conceptualde optar, de decidir, de romper, de proyectar, de rehacerse al rehacer el mundo, de soñar, si no hubieran llegado a ser capaces de evaluar, de dedicarse hasta el sacrificio al sueño por el cual luchan, de cantar y decantar el mundo, de admirar la belleza, no habría por qué hablar de la neutralidad de la educación. Pero tampoco habría por qué hablar de educación(Freire,2001:77).

El desafío de la educación religiosa para ser garante de tolerancia e inclusión, no se trata de que se generen currículas neutras y acríticas, ya que estas serían más bien asistémicas y antihumanas, su pretensión es establecer desarrollos curriculares que implementen el respeto y asimilen con naturalidad el concepto de alteridad; para el respeto de lo múltiple y de lo diverso, pero también asistiendo a la importancia de la singularidad de ser los humanos creaciones únicas en el universo, mensaje común de todas las visiones religiosas que la clase de religión debiera enarbolar y destacar.

\section{REFERENCIAS BIBLIOGRÁFICAS}

Ausubel, D. (2002). Adquisición y retención del conocimiento. Una perspectiva cognitiva. Ed. Paidós.Barcelona.

Bahai-Teaching. (10 de Abril de 2019). Bahai Teaching.org. Obtenido de https://bahaiteachings.org/que-es-enrealidad-esta-religion-bahai

Bahamondes, L. (2012). Una mirada a la metamorfosis religiosa en América Latina: nuevas ofertas de sentido en la sociedad. Revista Científica Guillermo de Ockham, Cali Colombia, 109-116.

Bauman, Z. (2003). Modernidad Líquida. Buenos Aires: Fondo de Cultura Económica.

Beck, U. (1998). La Sociedad del Riesgo, hacia una nueva modernidad . Barcelona : Paidós.

Belderraín, J. E. (2003). UNA LECTURA DE LAS TENDENCIAS MUNDIALES DESDE LAS SOCIEDADES MULTICULTURALES LATINOAMERICANAS. PERSPECTIVAS: Educación y religión:Los caminos de la tolerancia, 12-23.

Bordieu, P. (1997). Capital Cultural, Escuela y Espacio Social . México: Siglo Ventinuno Editores.

Castillo, L., \& Arias, R. (2016). Hallazgos de Investigación y reflexiones para la docencia. Bogotá: Editorial Kimpres S.A.S.

Connell, R. (1999). Escuelas y Justicia Social. Madrid: Ediciones Morata S.L.

Cordero, M. (2014). Manual práctico de pedagogía sistémica: Un itinerario para introducir la mirada sistémica en el aula. Mexico Distrito Federal: Editorial Grupo Cudec.

Da Silva, M. (2015). Ensino religiosos e ciencia das religioes: tensoes, desafíos e perspectivas. En Ensino Religioso Na Educacao Basica fundamentos epistemologicos y curriculares (págs. 135-153). Florianopolis: Saberes em dialogo.

De Souza, B. (2010). Decolonizar el Saber, reniventar el poder . Montevideo : Trilce.

Eisner, E., \& Vallance, E. (1974). Conflicting Concpetions of Curriculum. Chicago : The national Society for the study of education.

Fleuri, R. (2015). Interculturalidade, educacao e desafíos contemporaneos, diversidade religiosa, decolonidade e construcao da cidadania. En A. Pozzer, Palheta Francisco, Piovenzana Lionel, \& M. J. Torres, Ensino religioso na educacao basica fundamentos epistemologicos e curriculares (pág. 35 a 53). Florianopolis: Saberes em Dialogo.

Freire, P. (2001). Política y educación. Buenos Aires: Siglo XXI.

Guerrero, T. (2017). La ética del cuerpo, una tarea pendiente en los currículos latinoamerícanos . Ponencias IV Semiario Internacional de Artes Estética e Ética do Corpo . Belo Horizonte : PUC MINAS

MINEDUC. (12 de Septiembre de 1983). Biblioteca del Congreso. Recuperado el 3 de Septiembre de 2018, de Decreto $:$ https://www.leychile.cl/Navegar?idNorma $=16238$ 
Montecinos, C., Moya, L., Vargas, F., \& Berkowitz, D. (2017). Caracterización de la enseñanza de la religión a partir de la implementación del Decreto 924/1983 en las escuelas públicas de Chile. Santiago: MINEDUC y PNUD, Chile:.

Moya , L., \& Vargas, F. (2017). ¿Clases de religión en el sistema educativo público? Una revisión de los antecedentes internacionales. Revista electrónica de Educación Religiosa, 1-34.

Muñoz, D. (2013). La Fraternidad Ecuménica de Chile. Valparaíso, Chile: Alba S.A.

Muñoz, D. (2018). Ecumenismo y diálogo interreligioso a la luz de las conferencias episcopales Latinoamericanas( CELAM). Valparaiso: Editorial Alba.

Muñoz, D. (2018). Iglesia, ética y sociedad civil. Valparaiso: Editorial Alba.

Ocampo, A. (2014). Consideraciones epistemológicas para una educación inclusiva. Investigación y Postgrado Universidad Pedagógica Experimental Libertador, Venezuela, 83-111.

Ocampo, A. (2017). Pensar heterotópicamente la Educación Inclusiva. Polyphōnía. Revista de Educación InclusivaRevista del Centro de Estudios Latinoamericanos de Educación Inclusiva (CELEI), 17.

Ocampo, A. (2018 ). Educación Inclusiva: una teoría sin disciplina. Legados y recuperación de los saberes diaspóricos para una. Ponencia Presentada en I congreso Iberoamericano de Docentes, En prensa.

Pajer, F. (2015). Cómo y por qué Europa enseña las religiones en la escuela:. Revista Electrónica de Educación Religiosa, $1-24$.

Parker, C. (1993). Otra lógica en América Latina : religión popular y modernización. Santiago: Fondo de Cultura Económica Chile S.A.

Pozzer, A., \& Wickert, T. A. (2015). Ensino religioso intercultural: reflexoes, diálogos e implicacoes curriculares. En A. Pozzer, F. Palheta, L. Piovenza, \& M. J. Torres, Ensino religioso na educacao basica: fundamentos epistemologicos e curiculares (págs. 89-102). Florianopolis, Brazil: Saberes em Diálogo.

Rivard, J.-F., \& Amadio, M. (2003). Tiempo de enseñanza asignado a la educacion religiosa en los horarios oficiales. Perspectivas, UNESCO, 99-106.

Saleh, F. (19 de Noviembre de 2014). Sociedad Atea propone cambiar las clases de religión en colegios públicos. Santiago, Chile . Obtenido de El mostrador : http://www.elmostrador.cl/noticias/pais/2014/11/19/sociedadatea-propone-cambiar-las-clases-de-religion-en-colegios-publicos/

Scherz, T. (2015). La enseñanza de la religión en las escuelas: urgencia educativa para la esfera pública . Santiago: Arzobispado de Santiago. Vicaría para la Educación.

Souza, J. C. (2018). Surdez \& alteridade expressoes religiosas das criancas surdas. Sao Paulo: Fonte Editorial.

Tedesco, J. (2012). Educación y Justicia Social en América Latina. Buenos Aires: Fondo de Cultura Económica de Argentina, S.A.

Torres, J. (1998). El Curriculum Oculto . Madrid : Ediciones Morata.

Torres, J. (2012). Globalización e interdisciplinariedad el curriculum integrado. Madrid: Ediciones Morata.

Valenzuela, A. (Diciembre de 2018). ¿Cuántos profesores de religión existen en Chile? Revista Educar . (M. M. Illanes, Entrevistador)

Wimberley, J. (2003). La educacion para el dialogo intercultural e interreligioso: la nueva iniciativa del consejo de europa. Perspectivas, UNESCO, 85-98.

\section{Notas}

[1] En lo definido por (Benitez, 2008) existe la libertad psicológica, libertad moral, libertad de la voluntad, libertad sociológica, libertad interior ( libre albedrío), en la posición de Jean Paul Sartre, como visión del siglo XX el hombre está condenado a ser libre en esta época el concepto de libertad se refiere a la autonomía que posee el individuo en el seno de la sociedad y a la libertad política y civil garantizada por las sociedades democráticas."(Benítez, 2008: 600)

[2] El Consejo Nacional de Educación CNED, denomina modificación menor a las modificaciones curriculares tales como modificación de contenidos o bibliografía. 
Tatiana Patricia Guerrero Díaz. Educación valórica inclusiva y los desafíos de la educación religi...

[3]El Consejo Nacional de Educación CNED, denomina modificación mayor a las modificaciones curriculares que generan nuevos planes de estudios tales como el cambio de nombre de una asignatura o modificación de créditos u horas.

[4]Respecto al ecumenismo, es una tendencia que comienza a desarrollarse desde los años 60 y responde a la apertura católica romana iniciada en el Concilio Vaticano II" "La Fraternidad Ecuménica de Chile, es una entidad de carácter cristiana que acoge a las confesiones católica apostólica y romana, católica apostólica ortodoxa y protestantes evangélicas”(Muñoz, 2013:9)

[5]Te Deum es una expresión latina que significa : a ti Dios, en Chile tradicionalmente se realizan ceremonias evangélicas y católicas con motivo de agradecer y pedir a Dios su bendición en la celebración del mes de la Patria (Septiembre).

[6]En Chile son los apoderados quienes, al momento de matricular al estudiante en un establecimiento no confesional, completan una encuesta en la que manifiestan su voluntad de optar o no optar por la clase de religión católica, evangélica, otra o ninguna.

[7]Las Clases de religión en Chile se imparten en los colegios públicos, subvencionados y particulares que no declaran confesión religiosa, es decir son de carácter laico; y también pueden ser de índole confesional para las escuelas y colegios que si declaran pertenecer específicamente a una confesión religiosa particular y abrazar la doctrina específica de dicha religión o denominación cristiana por ejemplo el colegio bautista, colegio metodista, colegios católicos, etc.

[8]“Ser bahái significa, sencillamente, amar a todo el mundo; amar a la humanidad y tratar de servirla; trabajar por la paz y la hermandad universal” (Bahai-Teaching, 2019)

[9]Enseñar o instruir en una doctrina específica.

[10]Comisión Nacional de Educación Evangélica

[11]Traducción de la autora

[12]Traducción de la autora

[13]Traducción de la autora.

Los autores otorgan el permiso a compartir y usar su trabajo manteniendo la autoría del mismo.

\section{BY-NC}

